\title{
Detection of Salmonella-specific antibody in swine oral fluids
}

\author{
Briony M. Atkinson ${ }^{1}$, Bradley L. Bearson ${ }^{2}$, Crystal L. Loving ${ }^{1}$, Jeffrey J. Zimmerman ${ }^{3}$, Jalusa D. Kich ${ }^{1,4}$ and \\ Shawn M. D. Bearson ${ }^{1 *}$ (i)
}

\begin{abstract}
Salmonella is a leading cause of bacterial foodborne-related illness and pork products are a food-associated source. With $>50 \%$ of U.S. swine herds testing positive for Salmonella, asymptomatic carrier pigs that shed Salmonella in their feces are a food safety and environmental contamination issue. Herd level surveillance of Salmonella shedding status is useful, but collection of feces and culture methods for Salmonella detection are laborious and time-consuming. Surveillance for Salmonella-exposure through detection of Salmonella-specific serum antibody is a reliable method, but presents labor and animal-welfare issues. Oral fluids are a reliable, antemortem sample with proven utility for surveillance in the swine industry. We tested oral fluid samples as a potential non-invasive, repeatable sample type for the presence of Salmonella-specific antibodies. An indirect enzyme-linked immunosorbent assay (ELISA) detected anti-Salmonella IgG, IgM, and predominantly IgA in oral fluids from Salmonella enterica serovar Typhimurium-exposed pigs. Furthermore, with minor modifications, a commercial ELISA-based kit also detected Salmonella-specific antibodies in oral fluids. Collectively, oral fluids may serve as a prospective surveillance tool for herd level monitoring of Salmonella exposure.
\end{abstract}

Keywords: Salmonella, Swine, Oral fluids, Antibody detection

\section{Background}

Salmonella is a common source of bacterial foodbornerelated illness, with an estimated one million U.S. cases annually [1]. Salmonella was the causative agent of 762 foodborne outbreaks over the last 20 years, and pork products were the third highest associated food source with $10.8 \%$ attribution [2].

A 2006 study indicated that $>50 \%$ of swine production sites tested positive for Salmonella [3]. Identifying Salmonella-exposed herds is challenging because pigs are typically asymptomatic. Currently, surveillance for Salmonella on the farm is performed by bacteriological recovery of the organism in fecal samples or inferred through serological detection of Salmonella-specific antibodies. The swine industry could benefit from a Salmonella assay utilizing an antemortem sample with minimal animal stress and reduced labor for collection.

\footnotetext{
* Correspondence: shawn.bearson@ars.usda.gov

${ }^{1}$ Food Safety and Enteric Pathogens Research Unit, USDA, ARS, National

Animal Disease Center, 1920 Dayton Ave, Room 1403, Ames, IA 50010,

United States

Full list of author information is available at the end of the article
}

Oral fluids are commonly used to survey for infectious agents or antibody to specific organisms, and have improved whole herd surveillance programs [4-8]. To build on the utility of oral fluids for Salmonellaexposure surveillance, we used an immunoassay to detect Salmonella-specific antibody with oral fluids collected from pigs challenged with Salmonella enterica serovar Typhimurium (S. Typhimurium); the assay detected anti-Salmonella immunoglobulins (Ig) G, IgM, and predominantly IgA in oral fluids. Moreover, slight alterations to a commercial Salmonella antibody test for swine serum and meat juice samples detected anti-Salmonella immunoglobulins in oral fluids. Thus, detection of Salmonella-specific antibodies in oral fluids could function as a repeatable sample during the production cycle to provide not only timely surveillance information on Salmonella exposure and herd immunity, but also evaluate the effectiveness of disease intervention strategies against Salmonella.

(C) The Author(s). 2019 Open Access This article is distributed under the terms of the Creative Commons Attribution 4.0 International License (http://creativecommons.org/licenses/by/4.0/), which permits unrestricted use, distribution, and reproduction in any medium, provided you give appropriate credit to the original author(s) and the source, provide a link to the Creative Commons license, and indicate if changes were made. The Creative Commons Public Domain Dedication waiver (http://creativecommons.org/publicdomain/zero/1.0/) applies to the data made available in this article, unless otherwise stated. 


\section{Material and methods}

\section{Swine sample collection}

Experiment 1 . Eight-week-old cross-bred pigs $(n=3)$ testing negative for Salmonella in feces and for Salmonellaspecific antibody in serum were housed in ABSL-2 isolation at the National Animal Disease Center (NADC), Ames, IA. Pigs were intranasally inoculated with $1 \times 10^{10}$ nalidixic acid resistant $S$. Typhimurium strain UK-1 (SB377) [9]. Fecal samples were collected at 0, 2, and 14 days post-inoculation (dpi) for quantitative and qualitative Salmonella culture analyses, as previously described [10]. Samples were collected prior to challenge and at 34, 37, 43,49 , and $55 \mathrm{dpi}$ for oral fluids and 34, 37, 49, and $56 \mathrm{dpi}$ for serum. Oral fluids were collected by hanging cotton ropes (1/2", Web Rigging Supply, Lake Barrington, IL) for $\sim 30 \mathrm{~min}$ in the isolation room for the pigs to chew. The wet end of the rope was collected in a re-sealable plastic bag, and the bag was passed through a wringer (Dyna-jet BL-44, Overland Park, KS). Oral fluids were centrifuged (800×g, $20 \mathrm{~min}$ ), filtered (45um-pore-size), and stored at $-20{ }^{\circ} \mathrm{C}$ until assayed [11]. Blood was collected by venipuncture into $8.5 \mathrm{ml} \mathrm{BD}$ vacutainer serum separation tubes (BD, Franklin Lakes, NJ), centrifuged $(1500 \times g, 10$ $\mathrm{min})$, and serum stored at $-80^{\circ} \mathrm{C}$ [9].

Experiment 2. Eight-week-old cross-bred pigs $(n=14)$ were housed in ABSL2 isolation and intranasally inoculated with $1 \times 10^{9} \mathrm{SB} 377$. Feces, serum, and oral fluids were collected and processed prior to inoculation (D0 or D-5 (5 days prior to inoculation)) and 15 dpi (D15) as described above.

\section{Heat-inactivated Salmonella}

SB377 statically-grown $\left(37^{\circ} \mathrm{C}\right.$ overnight) in LB broth (Invitrogen, Carlsbad, CA) was pelleted, washed, and resuspended in phosphate buffered saline (PBS). Bacteria were incubated at $65^{\circ} \mathrm{C}$ for $45 \mathrm{~min}$, aliquoted, and stored at $-20{ }^{\circ} \mathrm{C}$ to serve as antigen in assays described below.

\section{Indirect enzyme-linked immunosorbent assay for Salmonella-specific antibody detection}

NUNC Immuno Maxisorp Flat bottom 96-well plates (Thermofisher, Wilmington, DE) were coated with 0.2 $\mathrm{ml}$ heat-inactivated SB377 at $1 \mu \mathrm{g} / \mathrm{ml}$ and incubated at $4{ }^{\circ} \mathrm{C}$ for $18 \mathrm{~h}$ in a humid chamber. Following 3 washes (PBS), blocking buffer (1\% bovine serum albumin (BSA) in PBS; B-PBS) was added $\left(1 \mathrm{~h}, 23-25^{\circ} \mathrm{C}\right)$. Oral fluids were diluted 1:2 with B-PBS. Serum was diluted 1:800 with B-PBS. Following $1 \mathrm{~h}$ incubation $\left(23-25^{\circ} \mathrm{C}\right)$, wells were washed $3 \mathrm{X}$ with $0.01 \%$ Tween 20 in B-PBS (B-PBS$\mathrm{T})$. Horseradish-Peroxidase conjugated antibody specific to swine IgA, IgM $(1 \mathrm{mg} / \mathrm{ml}$; Bethyl laboratories, Montgomery, TX) or IgG $(0.5 \mathrm{mg} / \mathrm{ml}$; Kirkegaard and Perry, Gaithersburg, MD) were diluted 1:20,000 and 1:80,000 in B-PBS-T for use in the oral fluid and serum ELISAs, respectively. Following $1 \mathrm{~h}$ incubation with secondary antibody $\left(23-25^{\circ} \mathrm{C}\right)$, plates were washed $3 \mathrm{X}$ with $\mathrm{PBS}$, and $3,3^{\prime}, 5,5^{\prime}$-tetramethylbenzidine (TMB) stabilized chromogen (Thermofisher, Wilmington, DE) added for 30 min $\left(23-25^{\circ} \mathrm{C}\right.$, dark). Reactions were stopped with 1 N Sulfuric Acid (Honeywell, Charlotte, NC), and optical density (OD) was read at $450 \mathrm{~nm}$ on a BioTek synergy/ HT microplate reader (BioTek, Winooski, VT) using GEN5 version 2.05 software. Results were reported as the average OD of duplicates of each sample. Limit of Detection (LOD) was calculated by determining the average OD and the standard deviation (SD) of the prechallenge samples, multiplying the SD by three, and adding that number to the average OD of the pre-challenge samples. Data was analyzed using GraphPad Prism 7 software (GraphPad software Inc., La Jolla, CA).

\section{IDEXX HerdChek swine Salmonella antibody assay}

In serum, porcine antibodies to Salmonella lipopolysaccharide (LPS) were measured as previously described using the IDEXX HerdChek Swine Salmonella Test Kit (IDEXX Europe B.V., Hoofddorp, Netherlands) [12]. To test oral fluids with the IDEXX kit, assay instructions were amended as follows: oral fluid was diluted 1:2 with sample diluent and incubated overnight $\left(23-25^{\circ} \mathrm{C}\right)$ in a humid chamber. Kit-supplied secondary antibody conjugate was incubated for $45 \mathrm{~min}\left(23-25^{\circ} \mathrm{C}\right)$; assay development followed manufacturer's recommendations. Reactions were measured at $\mathrm{OD}_{650}$ and converted to sample-topositive $(\mathrm{S} / \mathrm{P})$ ratios. Ratios $\geq 0.25$ were considered positive, while $<0.25$ were considered negative. Samples provided with the kit as positive and negative controls were used to calculate $S / P$ values for serum and oral fluid samples. In addition, oral fluids from experiment 1 was used as the negative ( $0 \mathrm{dpi})$ and positive $(55 \mathrm{dpi})$ controls to calculate the $\mathrm{S} / \mathrm{P}$ ratios for oral fluids from experiment 2 , and vice versa (using 15 dpi from experiment 2 as positive control).

\section{Results \& discussion}

To determine if Salmonella-specific antibodies could be detected in swine oral fluids, a proof-of-concept study was performed. Pigs were challenged with $S$. Typhimurium at $10^{10} \mathrm{CFU}$ (experiment 1) or $10^{9} \mathrm{CFU}$ (experiment $2)$, and at $2 \mathrm{dpi}$, pigs shed an average of $5.4 \times 10^{5}(+/-$ $3.1 \times 10^{5}$; standard error of the mean (SEM)) CFU/g feces (experiment 1) and $6.1 \times 10^{5}\left(+/-2.6 \times 10^{5}\right) \mathrm{CFU} / \mathrm{g}$ feces (experiment 2). By 14-15 dpi, Salmonella fecal shedding averaged $1.5 \times 10^{3}\left(+/-1.3 \times 10^{3}\right) \mathrm{CFU} / \mathrm{g}$ feces (experiment 1) and $3.5 \times 10^{2}\left(+/-1.3 \times 10^{2}\right) \mathrm{CFU} / \mathrm{g}$ feces (experiment 2). Using an isotype-specific, in-house ELISA for IgA, IgG, and IgM, Salmonella-specific circulating antibodies were detected in the sera of both groups of pigs in response to inoculation with Salmonella SB377 (Additional file 1: Figure S1). 
To determine if oral fluids contained antibodies against the $S$. Typhimurium strain, oral fluids collected at 34-55 dpi (experiment 1) and $15 \mathrm{dpi}$ (experiment 2) were tested using the ELISA for Salmonella-specific IgA, IgG, and IgM. All post-inoculation oral fluids measured above the limit of detection set by the pre-challenge oral fluid samples, especially Salmonella SB377-specific IgA (Figure 1); thus, Salmonella-specific antibodies were present in oral fluids following experimental Salmonella inoculation. Higher levels of the Salmonella-specific IgA isotype were observed in the oral fluids (Figure 1) compared to a higher abundance of the IgG and IgM isotypes typically measured in the sera samples (Additional file 1:
Figure S1). Neither serum nor oral fluid antibodies cross-reacted to Escherichia coli serotype O43:H28 strain 123 in the ELISA assay as all post-inoculation samples measured below the limit of detection set by the pre-challenge oral fluid samples $\left(\mathrm{OD}_{450 \mathrm{~nm}}=0.15\right)$ and pre-challenge sera samples $\left(\mathrm{OD}_{450 \mathrm{~nm}}=0.21\right)$.

We assessed if the anti-Salmonella immunoglobulins in oral fluids could be detected in the IDEXX HerdChek Swine Salmonella Test Kit, an ELISA assay commonly used in Europe to monitor Salmonella exposure [13, 14]. Although serum tested positive for antibodies to Salmonella LPS using the IDEXX assay (Additional file 1: Table S1), the oral fluids tested negative for antibodies using the kit-
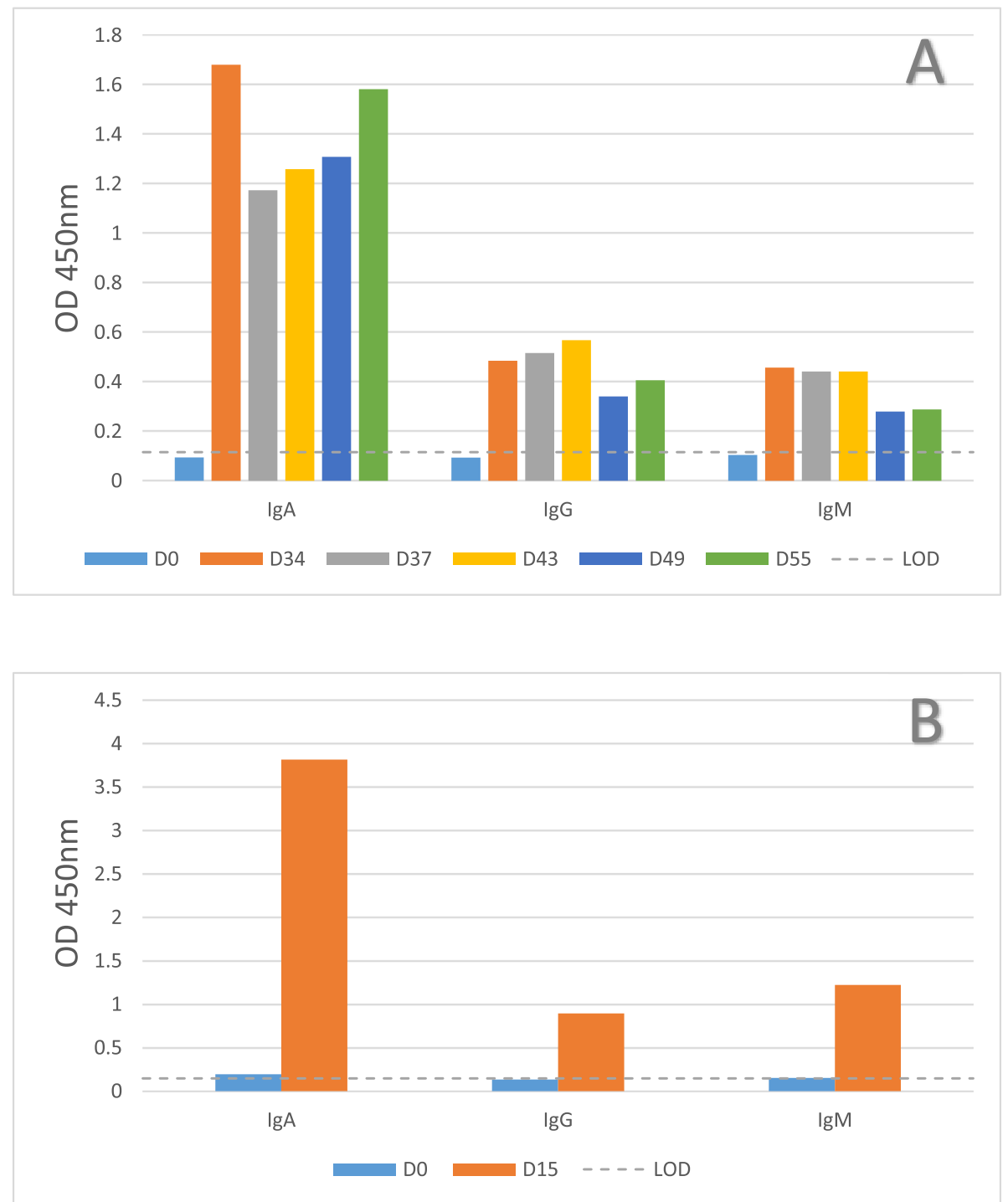

Fig. 1 Detection of anti-Salmonella immunoglobulins in swine oral fluids. Oral fluid samples were collected from S. Typhimurium UK-1 challenged pigs (SB377) at the indicated day (D) relative to inoculation. Samples were evaluated for Salmonella SB377-specific lgA, IgG, and IgM antibody in an in-house ELISA. Oral fluid samples are a herd level sample, therefore only a single data point is presented for each collection date. Results from experiment 1 ( $n=3$ pigs) are presented in panel $\mathbf{A}$ and from experiment $2(n=14$ pigs) in panel $\mathbf{B}$. The horizontal dotted line denotes the limit of detection (LOD) set by the pre-challenge oral fluid samples 
supplied positive and negative controls (Table 1, panel A). We presumed the lack of oral fluid antibody detection using the IDEXX assay was due to the nature of the proprietary controls supplied in the kit, which is assumed to be serum comprised of Salmonella-specific IgG and IgM, but containing little IgA; IgA was the predominant Salmonella SB377-specific isotype in the experimental oral fluids (based on Fig. 1). Alternatively, less antibody may be present in oral fluids, making it difficult to use the kit-supplied controls to calculate the sample-to-positive ratios. Therefore, we used oral fluids collected from Salmonella-inoculated pigs (positive control) and prior to inoculation (negative control) to calculate the sample-to-positive control ratios. All oral fluids collected after inoculation tested positive in the modified IDEXX assay, and the pre-inoculation oral fluids were negative (Table 1, panel B). Thus, Salmonella SB377-specific antibodies were detected in oral fluids using the IDEXX assay once the kit supplied controls for S/P calculation were replaced with oral fluid controls. Similar modifications were made by Kittawornrat et al. [5] to detect immunoglobulins against porcine reproductive syndrome virus (PRRSV) in oral fluids. The authors modified specific aspects of the IDEXX ELISA assay, including diluting the kit-supplied controls in order to calibrate the reactivity of the assay to the lower concentration of antibody present in oral fluids relative to sera. Our use of oral fluids as the negative and positive controls in the IDEXX assay achieved an analogous outcome. Furthermore, to compare IDEXX HerdCheck swine Salmonella ELISA results obtained from meat juice samples to sera samples, Wilhelm et al. applied a regression equation to recalculate the percent optical density data for meat juice samples in order to avoid underestimation of seroprevalence due to lower OD\% levels for meat juice samples [14]. For this commercial kit (or others) to be utilized to query swine oral fluid samples for Salmonella-specific antibodies, additional development is needed to optimize assay performance, including sensitivity and specificity validation. Altogether, the data suggested that commercially available IDEXX HerdChek Swine Salmonella Test Kit can identify Salmonella-specific immunoglobulins in pig oral fluids when using oral fluids to set $S / P$ ratios.

\section{Conclusion}

Our proof-of-concept study indicated that immunoglobulins against Salmonella are detectable in oral fluids. An oral fluid-based assay as a surrogate for serum could serve as a surveillance tool to ascertain on-farm Salmonella exposure, improve swine health management decisions, and evaluate intervention strategies. Furthermore, determination of Salmonella exposure using oral fluids could allow proactive classification of Salmonella herd status while using a non-invasive, antemortem collection method.

Table 1 Anti-Salmonella immunoglobulins are detected in swine oral fluids with slight modifications to the IDEXX HerdChek Swine Salmonella Test Kit

\begin{tabular}{|l|c|c|c|c|c|}
\hline & & \multicolumn{2}{|c|}{ A } & \multicolumn{2}{c|}{ B } \\
\hline & & \multicolumn{2}{|c|}{ Kit-supplied controls } & \multicolumn{2}{c|}{ Oral Fluid controls } \\
\hline & OD $_{650}$ & S/P & Status & S/P & Status \\
\hline Kit - control & 0.173 & & & & \\
\hline Kit + control & 2.312 & & & & 0.014 \\
\hline Exp 2, D0 & 0.099 & 0.0346 & - & 2.115 & + \\
\hline Exp 2, D15 & 0.409 & -0.1104 & - & -0.006 & - \\
\hline Exp 1, D0 & 0.097 & -0.0355 & - & 0.494 & + \\
\hline Exp 1, D34 & 0.252 & 0.0369 & - & 0.432 & + \\
\hline Exp 1, D37 & 0.233 & 0.0281 & - & 0.592 & + \\
\hline Exp 1, D43 & 0.283 & 0.0512 & - & 0.279 & + \\
\hline Exp 1, D49 & 0.186 & 0.0058 & - & 0.469 & + \\
\hline Exp 1, D55 & 0.245 & 0.0334 & - & -0.013 & - \\
\hline diluent & 0.095 & -0.0365 & - & & + \\
\hline
\end{tabular}

Oral fluid samples from experiment 2 served as the negative oral fluid control (D0, prior to inoculation) and positive oral fluid control (D15, post-inoculation) for calculating sample-to-positive (S/P) ratios for experiment 1 (orange highlight). Oral fluid samples from experiment 1 served as the negative oral fluid control (D0, prior to inoculation) and positive oral fluid control (D55, post-inoculation) for calculating S/P ratios for experiment 2 (gray highlight). S/P ratios for the oral fluid samples highlighted in yellow were calculated using the kit-supplied negative control ( - control) and positive control (+ control). S/P ratios were calculated using optical density (OD) measurements in the following formula:

$\mathrm{S} / \mathrm{P}=\left(\mathrm{OD}_{\text {sample }}-\mathrm{OD}_{\mathrm{NC}}\right) /\left(O \mathrm{D}_{\mathrm{PC}}-\mathrm{OD}_{\mathrm{NC}}\right)$

Ratios $\geq 0.25$ were considered positive while $<0.25$ were considered negative 


\section{Supplementary information}

Supplementary information accompanies this paper at https://doi.org/10. 1186/s40813-019-0136-7

Additional file 1: Figure S1. Detection of anti-Salmonella immunoglobulins in swine sera. Serum samples were collected from S. Typhimurium UK-1 challenged pigs (SB377) at the indicated day (D) relative to inoculation. Samples were evaluated for Salmonella SB377-specific $\lg A$, IgG, and IgM antibody in an in-house ELISA. Table S1. A. Experiment 1 sera samples in IDEXX HerdChek Swine Salmonella ELISA. B. Experiment 2 sera samples in IDEXX HerdChek Swine Salmonella ELISA.

\section{Abbreviations}

CFU: Colony forming units; dpi: days post-inoculation; ELISA: Enzyme-linked immunosorbent assay; IgA: Immunoglobulin A; IgG: Immunoglobulin G; IgM: Immunoglobulin M; LOD: Level of detection; OD: Optical density; S/ $\mathrm{P}$ : Sample-to-positive; SEM: Standard error of the mean

\section{Acknowledgements}

We thank Kellie Winter for her excellent technical assistance and the NADC animal care staff.

\section{Authors' contributions}

$\mathrm{SB}, \mathrm{BB}, \mathrm{JZ}, \mathrm{JK}$ conceived and participated in the study design. SB, BB, JK conducted the swine study. BA and $\mathrm{CL}$ created the Salmonella-specific immunoassays, BA performed immunoassays, and analyzed the data with SB and $C L$. All authors have read and approved the final version of the manuscript.

\section{Funding}

This research was supported by ARS-USDA CRIS funds.

\section{Availability of data and materials}

Data requests should be directed to the corresponding author.

\section{Ethics approval}

All experimental procedures involving the pigs were in compliance with the recommended principles described in the Guide for the Care and Use of Laboratory Animals by the National Research Council of the National Academies and were approved by the USDA-ARS, National Animal Disease Center, Animal Care and Use Committee.

Mention of trade names or commercial products in this article is solely for the purpose of providing specific information and does not imply recommendations or endorsement by the U.S. Department of Agriculture. The U.S. Department of Agriculture is an equal opportunity provider and employer.

\section{Consent for publication}

All authors gave their consent for publication.

\section{Competing interests}

The authors declare no conflicts of interest.

\section{Author details}

${ }^{1}$ Food Safety and Enteric Pathogens Research Unit, USDA, ARS, National Animal Disease Center, 1920 Dayton Ave, Room 1403, Ames, IA 50010, United States. ${ }^{2}$ Agroecosystems Management Research Unit, USDA, ARS, National Laboratory for Agriculture and the Environment, Ames, IA, United States. ${ }^{3}$ College of Veterinary Medicine, lowa State University, Ames, IA, United States. ${ }^{4}$ Embrapa Swine and Poultry, Concórdia, SC, Brazil.

Received: 19 September 2019 Accepted: 25 November 2019 Published online: 16 December 2019

\section{References}

1. Scallan E, Hoekstra RM, Angulo FJ, Tauxe RV, Widdowson MA, Roy SL, Jones $J$, Griffin PM. Foodborne illness acquired in the United States--major pathogens. Emerg Infect Dis. 2011;17(1):7-15.

2. Interagency Food Safety Analytics Collaboration. Foodborne illness source attribution estimates for 2016 for Salmonella, Escherichia coli O157, Listeria monocytogenes, and Campylobacter using multi-year outbreak surveillance data, United States. GA and D.C.: U.S. Department of Health and Human Services, CDC, FDA, USDA-FSIS. 2018. https://www.cdc.gov/foodsafety/ifsac/ pdf/P19-2016-report-TriAgency-508.pdf. Accessed 12/07/2019.

3. NAHMS. Salmonella on U.S. Swine Sites - Prevalence and Antimicrobial Susceptibility, National Animal Health Monitoring System Swine 2006, N536.0109 ed. United States Department of Agriculture, Animal and Plant Health Inspection Service. 2009. https://www.aphis.usda.gov/animal_health/nahms/swine/ downloads/swine2006/Swine2006_is_salmonella.pdf. Accessed 12/07/2019.

4. Bjustrom-Kraft J, Woodard K, Giménez-Lirola L, Rotolo M, Wang C, Sun Y, Lasley P, Zhang J, Baum D, Gauger P, Main R, Zimmerman J. Porcine epidemic diarrhea virus (PEDV) detection and antibody response in commercial growing pigs. BMC Vet Res. 2016;12:99.

5. Kittawornrat A, Prickett J, Wang C, Olsen C, Irwin C, Panyasing Y, Ballagi A, Rice A, Main R, Johnson J, Rademacher C, Hoogland M, Rowland R, Zimmerman J. Detection of porcine reproductive and respiratory syndrome virus (PRRSV) antibodies in oral fluid specimens using a commercial PRRSV serum antibody enzyme-linked immunosorbent assay. J Vet Diagn Investig. 2012;24(2):262-9.

6. Panyasing Y, Goodell CK, Giménez-Lirola L, Kittawornrat A, Wang C, Schwartz KJ, Zimmerman JJ. Kinetics of influenza a virus nucleoprotein antibody (lgM, lgA, lgG) in serum and oral fluid specimens from pigs infected under experimental conditions. Vaccine. 2013;31(52):6210-5.

7. Bjustrom-Kraft J, Christopher-Hennings J, Daly R, Main R, Torrison J, Thurn M Zimmerman J. The use of oral fluid diagnostics in swine medicine. J Swine Health Prod. 2018;26(5):262-9.

8. Prickett JR, Zimmerman JJ. The development of oral fluid-based diagnostics and applications in veterinary medicine. Anim Health Res Rev. 2010;11(2):207-16.

9. Bearson BL, Bearson SMD, Brunelle BW, Bayles DO, Lee IS, Kich JD. Salmonella DIVA Vaccine reduces disease, colonization and shedding due to virulent S. Typhimurium infection in swine. J Med Microbiol 2017;66(5):651-661.

10. Bearson BL, Bearson SM. The role of the QseC quorum-sensing sensor kinase in colonization and norepinephrine-enhanced motility of Salmonella enterica serovar Typhimurium. Microb Pathog. 2008;44(4):271-8.

11. Hughes HR, Vincent $A L$, Brockmeier SL, Gauger PC, Pena L, Santos J, Braucher DR, Perez DR, Loving CL. Oral fluids as a live-animal sample source for evaluating cross-reactivity and cross-protection following intranasal influenza a virus vaccination in pigs. Clin Vaccine Immunol. 2015;22(10):1109-20.

12. Bearson BL, Bearson SMD, Kich JD, Lee IS. An rfaH mutant of Salmonella enterica serovar Typhimurium is attenuated in swine and reduces intestinal colonization, fecal shedding and disease severity due to virulent Salmonella Typhimurium. Front Vet Sci. 2014;1:9.

13. Mousing J, Jensen PT, Halgaard C, Bager F, Feld N, Nielsen B, Nielsen JP, Bech-Nielsen S. Nation-wide Salmonella enterica surveillance and control in Danish slaughter swine herds. Prev Vet Med. 1997;29(4):247-61.

14. Wilhelm E, Hilbert F, Paulsen P, Smulders FJ, Rossmanith W. Salmonella diagnosis in pig production: methodological problems in monitoring the prevalence in pigs and pork. J Food Prot. 2007;70(5):1246-8.

\section{Publisher's Note}

Springer Nature remains neutral with regard to jurisdictional claims in published maps and institutional affiliations.

\section{Ready to submit your research? Choose BMC and benefit from:}

- fast, convenient online submission

- thorough peer review by experienced researchers in your field

- rapid publication on acceptance

- support for research data, including large and complex data types

- gold Open Access which fosters wider collaboration and increased citations

- maximum visibility for your research: over $100 \mathrm{M}$ website views per year

At $\mathrm{BMC}$, research is always in progress.

Learn more biomedcentral.com/submission 